\title{
Evaluating the effect of non-Newtonian fluid turbulent flowing for blood within a double-stenosed artery
}

\author{
Mohammed Ghalib Al-Azawy
}

\begin{abstract}
Affiliations
Department of Mechanical Engineering, Wasit University, Wasit, Iraq

\section{Correspondence}

Mohammed G. Al-Azawy,

Department of Mechanical

Engineering, Wasit University,

Wasit, Iraq

Email:

mgalazawy@uowasit.edu.iq

Received

29-October--2021

Revised

13-November -2021

Accepted

17-November-2021

Doi: 10.31185/ejuow.Vol9.Iss2.233
\end{abstract}

\begin{abstract}
This article describes the numerical investigation of blood rheology within an artery that includes two narrowing areas via Computational Fluid Dynamics (CFD) to offer guidance to the community, especially surgeons, and help them to avoid the risk of stenosis. Elliptic blending Reynolds stress model and two models of viscosity have been used in this investigation utilizing STARCCM+ 2021.2.1. The test model includes two elliptical stenosis with a $2 \mathrm{~mm}$ distance between them, and the area of stenosis is $75 \%$. Results of normalized axial velocity, turbulent kinetic energy (TKE) and turbulent viscosity ratio (TVR) were evaluated before, through and after the stenosis in order to predict and avoid the real problems that occur from changing the area of the artery. Furthermore, Fractional flow reserve (FFR) was employed to assess the level of risk of stenosis through the artery, which depends on pressure measurements. Corresponding to the author's observation, it was found that the recirculation regions in the area between the stenosis are larger than the area after the stenosis. Moreover, the results of TKE and TVR are almost identical through and downstream of the stenosis, whereas the TKE is slightly higher with the Carreau model (arrive to $0.54 \mathrm{~J} / \mathrm{kg}$ ) than with the Newtonian flow (arrive to $0.47 \mathrm{~J} / \mathrm{kg}$ ) at the upstream and through the first stenosis.
\end{abstract}

Keywords: Artery stenosis, computational fluid dynamics, non-Newtonian fluid flow, turbulent flow.

الخلاصة: تصف هذه المقالة التحقيق العددي لجريـان الدم خـلال شريان يتضمن منطقتين ضيقتين بتقنية ديناميكيات السو ائل العدديـة (CFD) لتقديم

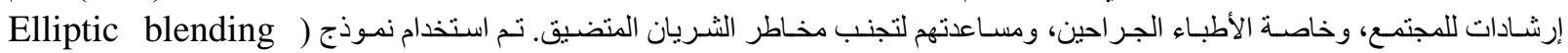

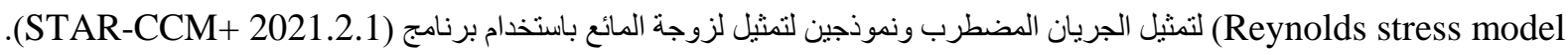

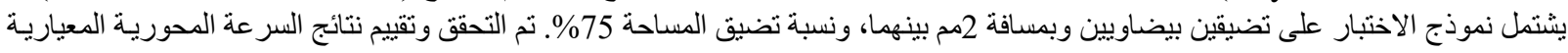

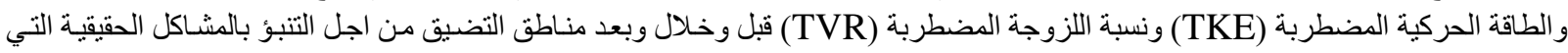

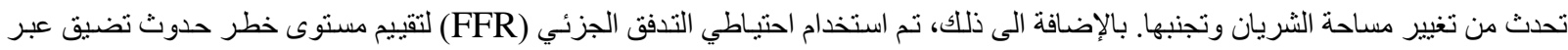

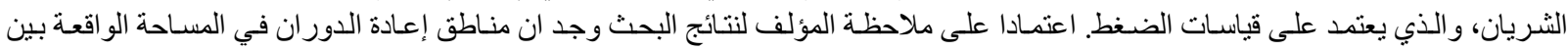

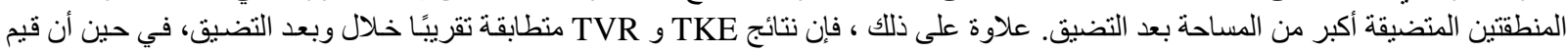

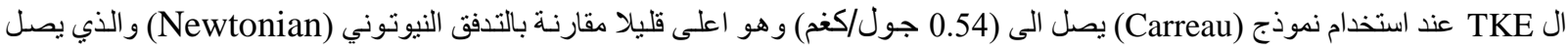
الى (0.47 جول/كغم) قبل وخلال التضيق الأول.

\section{INTRODUCTION}

The development of fatty material called plaque causes arterial disease, which is a narrowing or blockage of the arteries. In general, cholesterol and other lipids precipitate behind the intima of the artery's wall, causing stenosis, which reduces the artery's cross-sectional area and causes blood flow to turn from laminar to turbulent. Hemodynamic variables like shear stress, turbulent kinetic energy, and wall pressure play a crucial role in eroding and weakening the artery's inner wall in the post-stenosis of the turbulent zone. For example, turbulence-induced high wall shear stresses have a significant influence on vessel damage [1]. The study of stenotic flow under the assumption that blood is a homogenous and Newtonian fluid has received a lot of attention in recent decades. 
However, blood is an incompressible non-Newtonian fluid [2]. Furthermore, the viscosity of blood rises when shear rates fall below $100 \mathrm{~s}^{-1}$ and non-Newtonian blood characteristics are shown [3], particularly when shear rates fall below $10 \mathrm{~s}^{-1}$ [4]. Only few researches on non-Newtonian, turbulent with double stenosis blood flow assessment in a narrower artery have been identified in the literature. A study by the present author assumed the blood as laminar and two models of viscosity have been used [5]. In this work the shape of the single stenosis was trapezoidal; while in the present work the present author expands the work to evaluate the blood flow within two stenosis utilizing turbulence. A recent study by Kadhim et al. assumed the blood as laminar through a left coronary artery with the presence of different double stenosis [6]. The effect of viscosity models were examined by Neofytou and Drikakis [7] utilizing three different models: power-law, Casson, and Quemada models. The authors discovered that the findings produced by these models and the Newtonian varied significantly and that the development of vortex, wall shear stress, and separation following stenosis are all dependent on the specifics of the viscosity model employed in the simulation. Recent work by Paul et al.[8] and Molla et al. [9] investigate blood flow in narrowing artery and proposes the LES method as a solution, the authors assumed the flow as Newtonian pulsatile turbulent blood flow. Rabby et al. [10] investigated the unsteady periodic blood flow numerically within a 2D pipe with two stenosis of $75 \%$ and $50 \%$, respectively. The authors assumed the flow as laminar and utilized different models of viscosity and examined the streamwise velocity, wall shear stress, pressure, vorticity, and vector through the model, concluding that there was a lower risk of thrombogenesis behind the stenosis and inadequate blood supply to the body in the Newtonian flow compared to the non-Newtonian model.

In 2015, the present author investigated different turbulent models to assess the impact of these models on blood flow through a positive displacement pump [11]. Al-Azawy et al. [12] Continued the work by investigating the effect of non-Newtonian models. According to these papers, the turbulence model of elliptic blending Reynolds stress model and Carreua model gave the best accurate forecast across much of the flow via a medical device such as blood pumps and arteries. Therefore, in this work, a Carreau with a turbulent model were employed to evaluate blood flow formation through a three dimensional double stenosis artery with high Reynolds number using STAR-CCM+ 2021.2.1 (16.04.012-R8).

Nonetheless, in order to determine the degree of artery issues, a parameter must be addressed. Fractional Flow Research (FFR) is a technique that may be used to achieve this goal. FFR was initially described by Pijls et al., who used pressure estimations in the absence of stenosis [13]. FFR has been shown to be reliable in identifying stenosis severity [14].

Several studies investigated the blood flow and FFR effects of mono stenosis. Gashi et al. predicted the FFR of single stenosis with different stenosis severities [15]. In what follow, the current author builds on the preliminary work by Kadhim et al. [6]; the research was restricted to double stenosis laminar flow without FFR. Therefore, the current study broadens its scope to cover the FFR level across two stenosis with a turbulence model at a high Reynolds number.

The important aim of this work is to offer guidance to the community, especially surgeons, on how to get benefit from the investigation of various models of viscosity and turbulence with comparing this to the Newtonian flow at high Reynolds number. Examining these effects utilizing normalized axial velocity, vector, turbulent kinetic energy and turbulent viscosity ratio, to determine the amount of risk associated with the existence of two stenosis or narrowing through the artery.

\section{METHODODLOGY}

\subsection{Case description}

In the present simulation, a model of 3D stenosis artery is constructed. Figure 1 illustrates this model of artery, which shows the position of two blockage areas. As shown in Figure 1b, the length of each stenosis is $6 \mathrm{~mm}$, the distance between these two stenosis is $2 \mathrm{~mm}$, and the diameter of the artery is $3 \mathrm{~mm}$. The radius of stenosis is 0.38 $\mathrm{mm}$; furthermore, the area of stenosis (AS) is found as [16]: percentage of AS $=\left(1-r_{s} / r_{a}\right) \times 100 \%$, where $r_{a}$ is the radius of artery $(1.5 \mathrm{~mm})$ and $r_{s}$ is the radius of stenosis. In the present work, the AS is $75 \%$. 


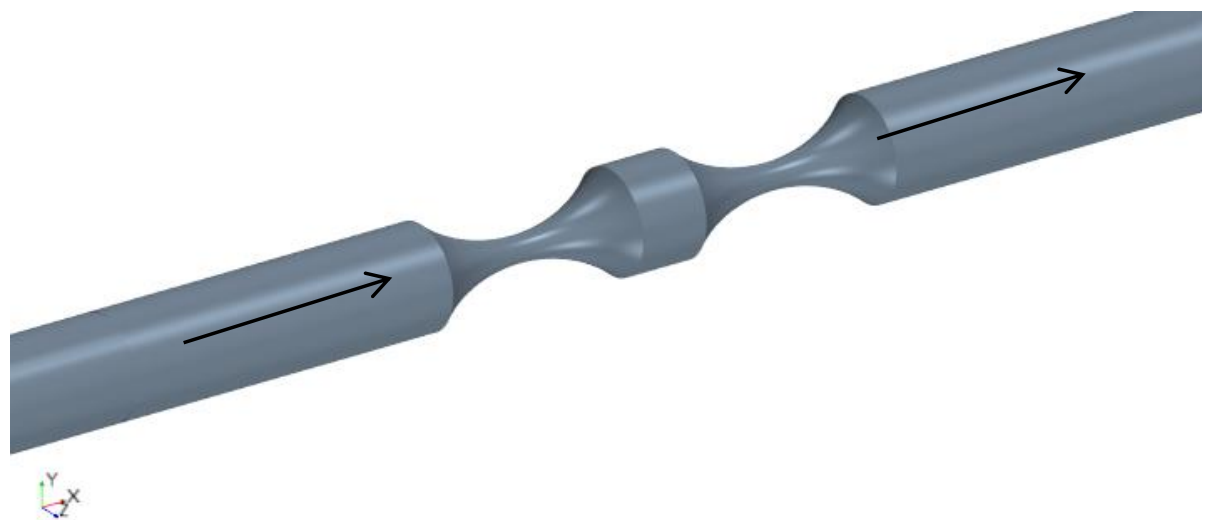

(a) Three-dimensional model.

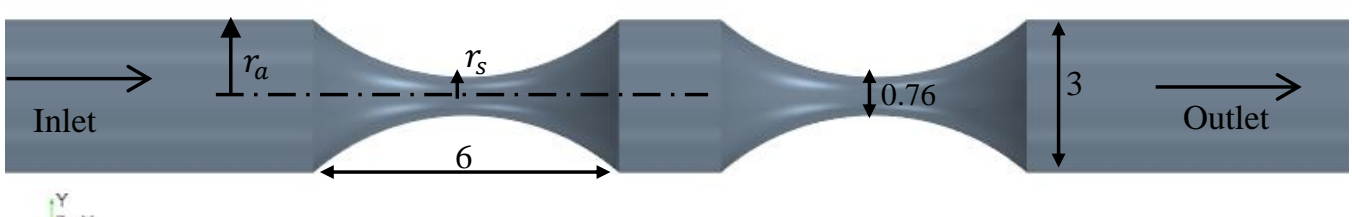

(b) Dimensions of the test case (all dimentions in $\mathrm{mm}$ ).

Figure 1 Model geometry.

\subsection{Computational details}

A model of 3D computational geometry of double stenosis artery was performed numerically using a commercial CFD software STAR-CCM+ 2021.2.1 (16.04.012-R8) [17]. In this software, the steady Navier-Stokes equations were solved using a finite volume method as follows [18]:

$$
\begin{gathered}
\frac{\partial u_{i}}{\partial x_{i}}=0 \\
\rho u_{j} \frac{\partial u_{i}}{\partial x_{j}}=-\frac{\partial p}{\partial x_{j}}+\frac{\partial}{\partial x_{j}}\left[\mu(S) \frac{\partial u_{i}}{\partial x_{j}}-\overline{u_{i} u_{j}}\right]
\end{gathered}
$$

Where the velocity gradient is $u_{i}=(u, v, w)$, the Cartesian coordinate is $x_{i}=(x, y, z)$, the pressure is $p$, $\overline{u_{i} u_{j}}$ is Reynolds stress tensor and the density is $\rho$. While $\mu(S)$ is the blood viscosity, which is dependent on the shear rate magnitude, which is calculated as follows from the shear rate tensor [18]:

$$
S=\sqrt{2 S_{i j} S_{i j}}, \text { where } S_{i j}=\frac{1}{2}\left(\frac{\partial u_{i}}{\partial x_{j}}+\frac{\partial u_{j}}{\partial x_{i}}\right)
$$

All simulated conditions had the similar input velocity (the average inlet velocity is $2.3 \mathrm{~m} / \mathrm{s}$ ), outflow boundary condition, and no-slip conditions applied to the walls.

In addition, five separate meshes were built to evaluate the spatial mesh resolution demands for the 3D simulations, as shown in Table 1. Polyhedral mesh was used for the CFD model in this investigation using STAR$\mathrm{CCM}+2021.2 .1$ (16.04.012-R8) [17], as shown in Figure 2. In addition, to address the boundary layer, four layers for prism layer were used. The non-dimensional distance to the first near-wall grid point, $\mathrm{y}^{+}=\mathrm{y}^{\mathrm{a}} / \mu \sqrt{\rho \tau_{\mathrm{w}}}$, is also used to evaluate near wall accuracy; where $\mu$ is the blood viscosity, $\mathrm{y}$ is the distance from the wall to the first cell centre, $\rho$ is the density of blood and $\tau_{\mathrm{w}}$ is the wall shear stress [17]. In all the present simulation cases, this was set to recommended value of $\mathrm{y}^{+} \geq 1$ for upstream and downstream of stenosis, and within $\mathrm{y}^{+} \geq 2.7$ through the stenosis (see Figure 3). 
The behaviour of axial velocity along a horizontal line through a stenosis region was presented in Figure 4, which demonstrate a grid-independency test. As shown in this graph, the velocity predictions for the meshes M4 and M5 are relatively similar in comparison to the other three meshes. As a result, for the next simulation, the mesh M4 (1080189 cells) is chosen to represent the fluid characteristics throughout the entire model.

Table 1 Details of mesh models

\begin{tabular}{|l|l|l|l|l|l|}
\hline Meshes & M1 & M2 & M3 & M4 & M5 \\
\hline $\begin{array}{l}\text { Total number of } \\
\text { cells }\end{array}$ & 235949 & 479320 & 761086 & 1080189 & 1548580 \\
\hline
\end{tabular}
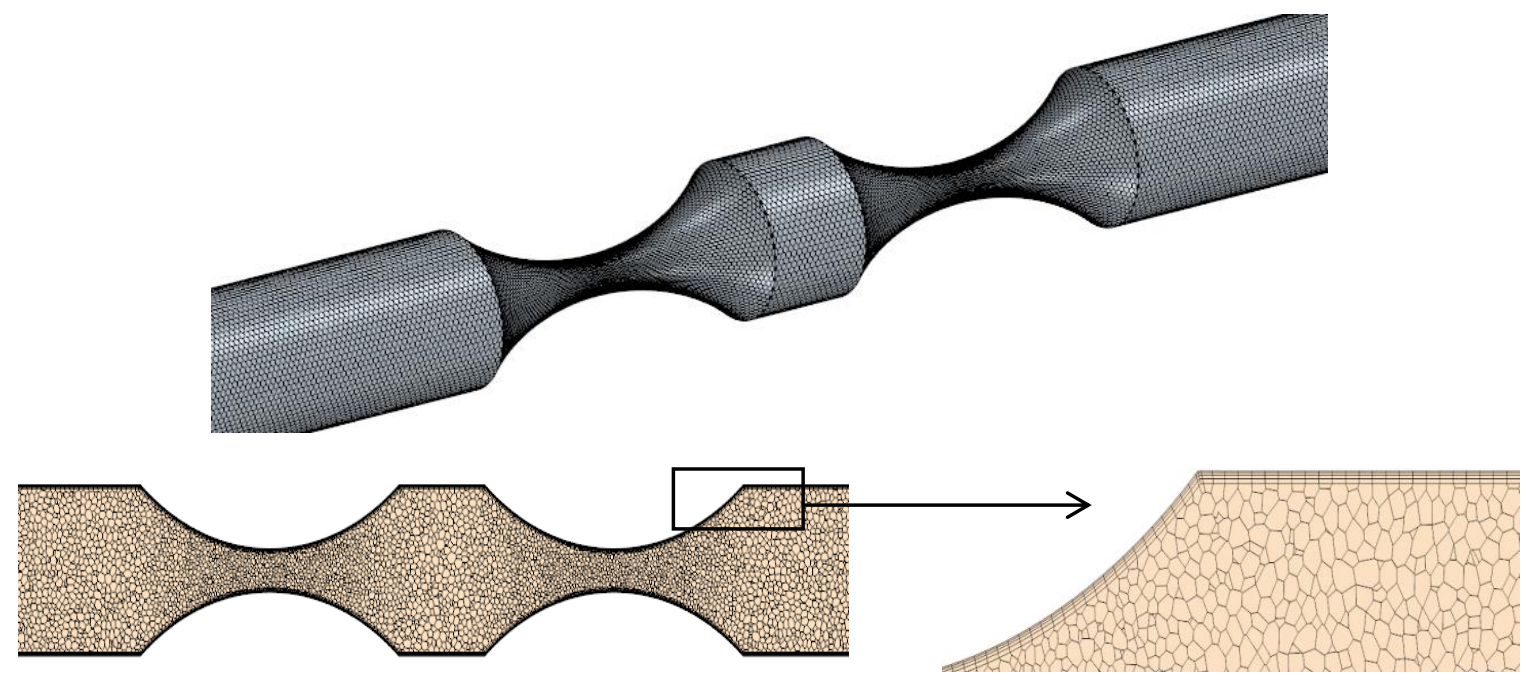

Figure 2 Mesh arrangements showing the prism layer with polyhedral mesh.
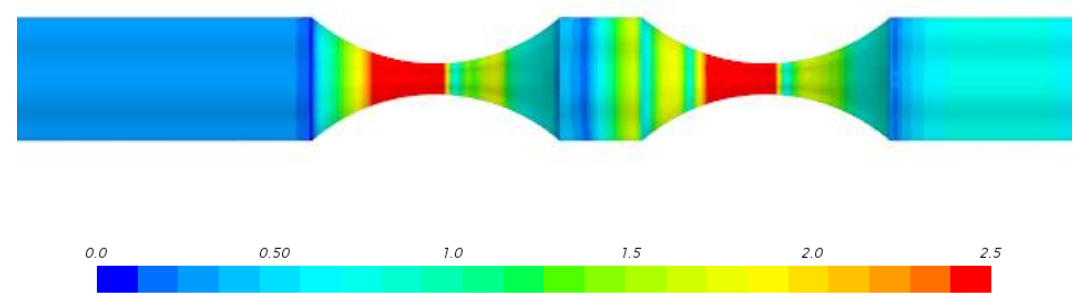

Figure 3 Contour of non-dimensional distance to the first near-wall grid point $y^{+}$. 


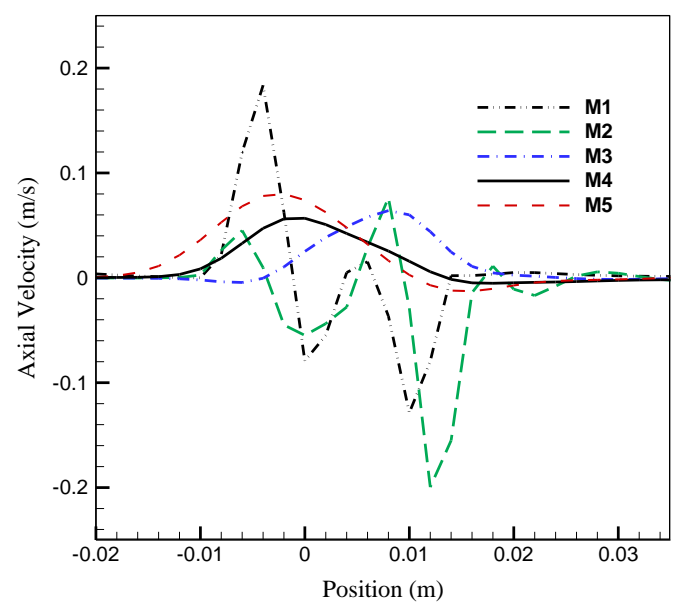

Figure 4 Plot of Axial velocity along a horizontal centreline.

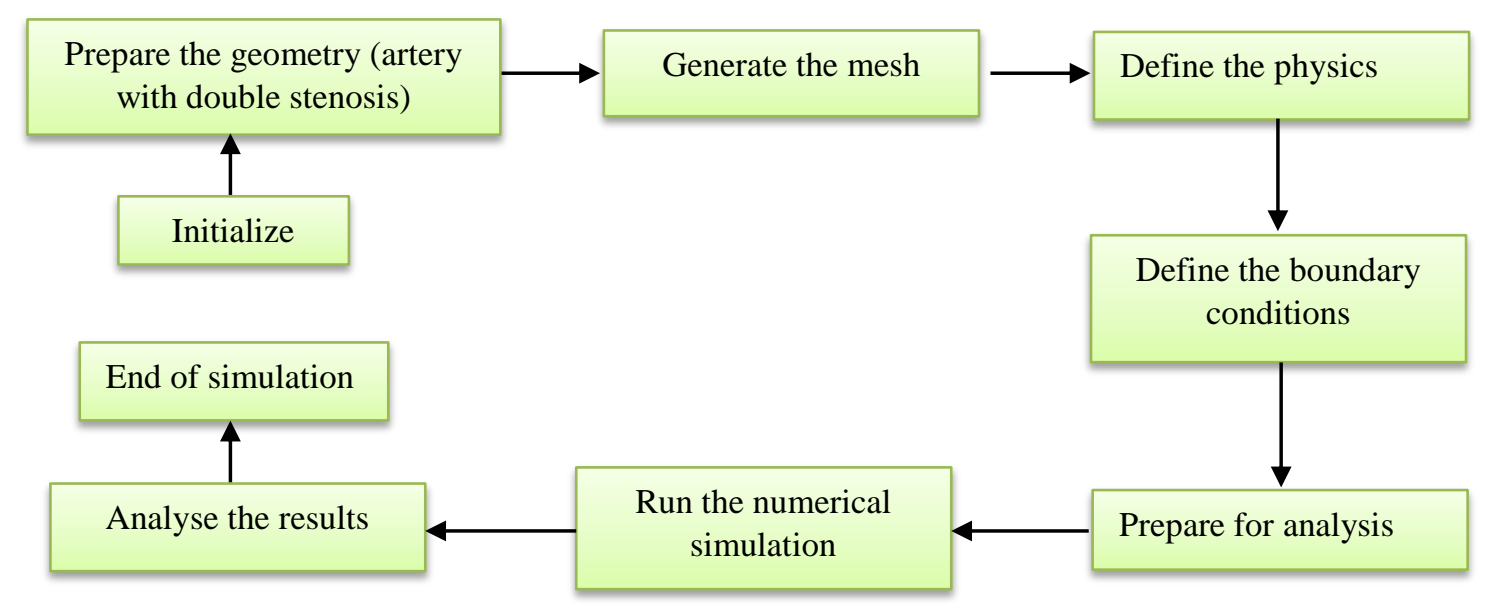

Figure 5 A flowchart showing the sequence of CFD setup.

\subsection{Modelling of blood rheology and turbulence}

In the present work, the blood is modelled as non-Newtoniana, the Carreaue model has been chosen because of the reasonable prediction behaviour of blood with using this model according to previous conclusion of the present author [12][5] and other researchers[19][20].

The Carreau model takes the following shape; [21]:

$$
\mu(S)=\mu_{\infty}+\left(\mu_{0}-\mu_{\infty}\right)\left(1+(\lambda S)^{2}\right)^{(n-1) / 2}
$$

Where the values of the parameters that appears in the above equation is presented in Table 2. 
Table 2 Values of parameters of equation 3 [21]

\begin{tabular}{|c|c|c|c|c|}
\hline Parameter & $\mu_{0}$ & $\mu_{\infty}$ & $\lambda$ & $n$ \\
\hline Value & 0.056 Pa.s & 0.00345 Pa.s & $3.313 \mathrm{~s}$ & 0.3568 \\
\hline
\end{tabular}

$\mu_{0}$ : Viscosity of blood at zero shear rate.

$\mu_{\infty}$ : The infinite shear viscosity.

$\lambda$ : The relaxation time constant.

Taking into account the effect of turbulence in arteries with presence of narrowing play an essential role and important in order to predict the real problems that arise from this change in area of artery. Therefore, in the present study, the model of elliptic blending Reynolds stress model was chosen, suggested by [22] and revised by [23] , since this model offer superior capability especially with low Reynolds number [24].

\section{RESULTS AND DISCUSSION}

\subsection{Observation of flow field}

The axial velocity of the current numerical simulation was first validated by comparing it to the existing experimental data of nozzle provided by the Food and Drug Administration (FDA) [25] (see Figure 6) . As indicated in the figure, traces of axial velocity magnitude were given at a line placed at the outflow portion.

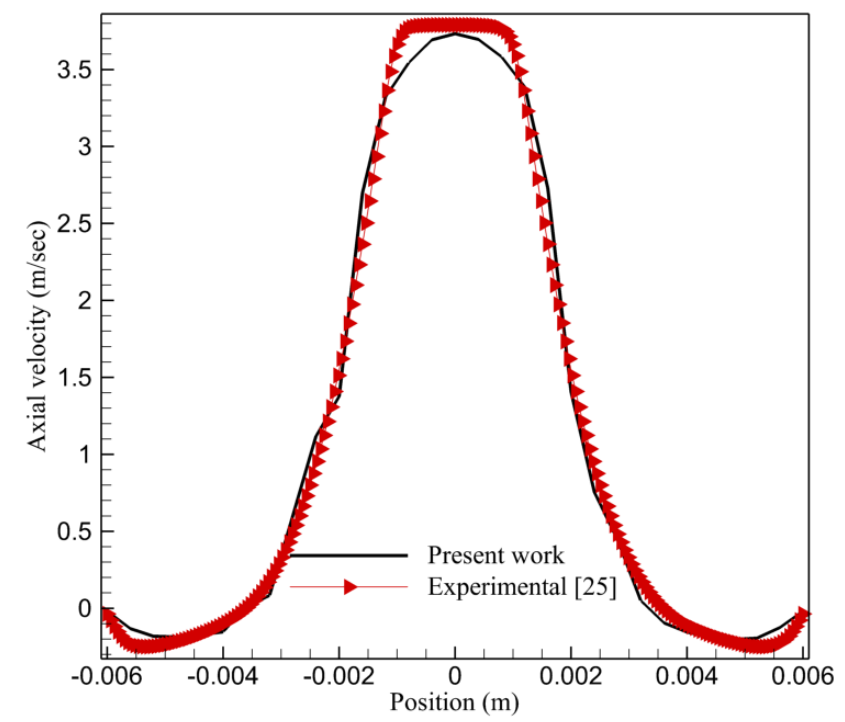

Figure 6 Variation of axial velocity at line of the present work and the experimental data of [25].

Figure 7 depicts the velocity vector with the viscous effects of working fluid (blood) on the evolution of flow at mid-plane along the streamwise. From this figure, for both models, it can be seen that the recirculation regions growth after the stenosis especially after the first one (see Figure $7 \mathrm{a}$ and b); and these regions are slightly bigger with Carreau than the Newtonian model this is due to separation of shear layers and flow. This behaviour of flow is clearer in Figure 7. Figure 8 presents the normalised axial velocity for both models at lines that oriented vertically as illustrated in the figure. The axial velocity were extracted and normalized with respect to the average inlet velocity as follows:

$$
\text { Axial velocity } \text { normalized }=\frac{\text { Axial velocity of blood }}{\text { average inlet velocity }}
$$

From these figures, for clarity some recirculation regions are enclosed with circles as example (see Figure 8 a and b). Furthermore, the recirculation regions are much in the area between the stenosis since of complexity of flow in this small area which develops the vortices and the separation in blood flow. 


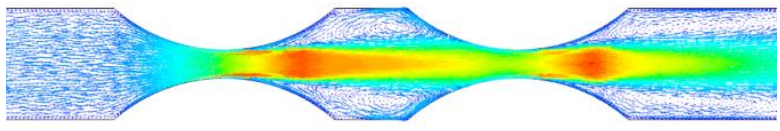

(a) Newtonian

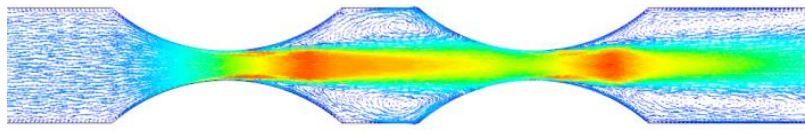

(b) Non-Newtonian

velocity magnitude $(\mathrm{m} / \mathrm{s})$

$z^{x} x$

0.0

12.0

16.0

20.0

$24.0 \quad 28.0$

$\begin{array}{lll}32.0 & 36.0 \quad 40.0\end{array}$

Figure 7 Plot of vector at mid plane for different models of viscosity: (a) Newtonian and (b) Non-Newtonian.

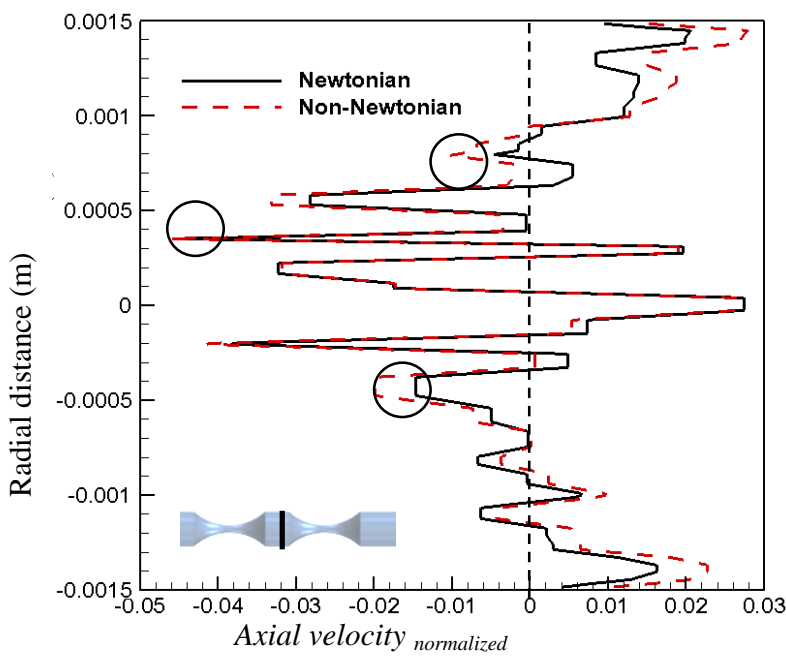

(a)

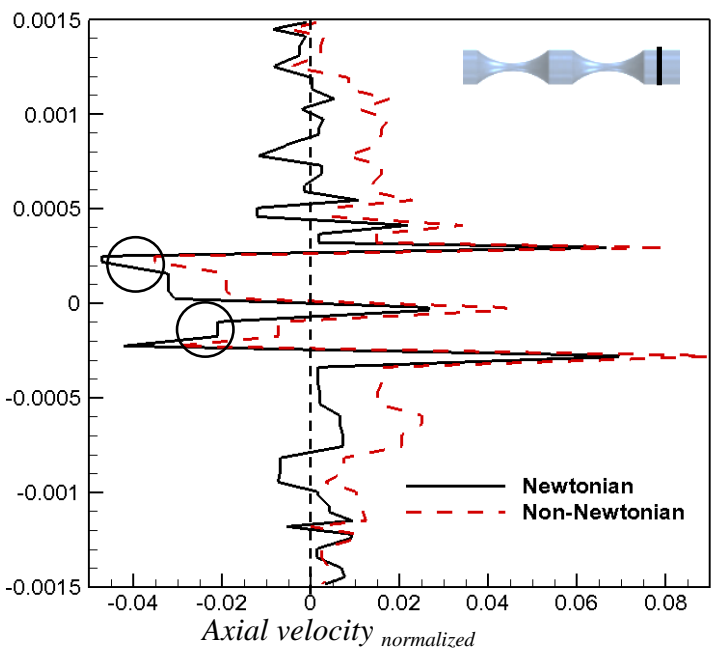

(b)

Figure 8 Evolution of normalized axial velocity for Newtonian and non-Newtonian flow: (a) vertical line 1 at distance 0.5 $\mathrm{mm}$ from the centre and (b) vertical line 2 at distance $7.5 \mathrm{~mm}$ from the centre.

\subsection{Fractional flow reserve (FFR)}

FFR is one of the best techniques that use to assess the level of stenosis through the arteries and as index for closure the artery. In general, FFR depends on the pressure measurements before and after the stenosis and calculates as [13]:

$$
\mathrm{FFR}=\frac{\mathrm{P}_{\text {distal }}}{\mathrm{P}_{\text {proximal }}}
$$

Where $\mathrm{P}_{\text {proximal }}$ is the pressure before the stenosis and pressure after the stenosis is denoted as $\mathrm{P}_{\text {distal }}$. Table 2 presents the value of FFR at distances $(8,12$ and $16 \mathrm{~mm}$ ) from the centre (before and after the centre of stenosis). Overall, non-Newtonian FFR values are lower than Newtonian FFR values, indicating that non-Newtonian influences are likely to be involved.

Table3 the value of FFR at distances 8, 12 and 16 downstream and upstream of the stenosis.

\begin{tabular}{|c|c|c|c|}
\hline \multirow{2}{*}{ Model of viscosity } & \multicolumn{3}{|c|}{ FFR } \\
\cline { 2 - 4 } & at 8 & at 12 & at 16 \\
\hline Newtonian & 0.6850 & 0.67785 & 0.6754655 \\
\hline Non-Newtonian & 0.60385 & 0.59446 & 0.58934 \\
\hline
\end{tabular}




\subsection{Prediction's effect of TKE and TVR}

This section will explain some of the acquired results that are linked to turbulent flow characteristics. Figure 9 depicts the turbulent kinetic energy at different vertical lines before, through and after the double stenosis. At the same lines, the Turbulent Viscosity Ratio (TVR) was investigated and illustrated in Figure 10. Whereas the contour of TVR was depicted in Figure 11 for both models of viscosity. It can be seen that the TKE and TVR are almost identical through and downstream the stenosis whereas the TKE be slightly higher with Carreau model than the Newtonian flow at the upstream and through the first stenosis while the reverse behaviour was noticed for TVR, which being lower in the case of Carreau model. This is due to the high velocity through and upstream of the stenosis, which results in a high Reynolds number, causing the velocity to reach to $40 \mathrm{~m} / \mathrm{s}$ (see Figure 7). Because of the oscillations in the viscosity, the peak TKE occurs downstream of the stenosis, especially when it is distant from the stenosis (see Figure 9).
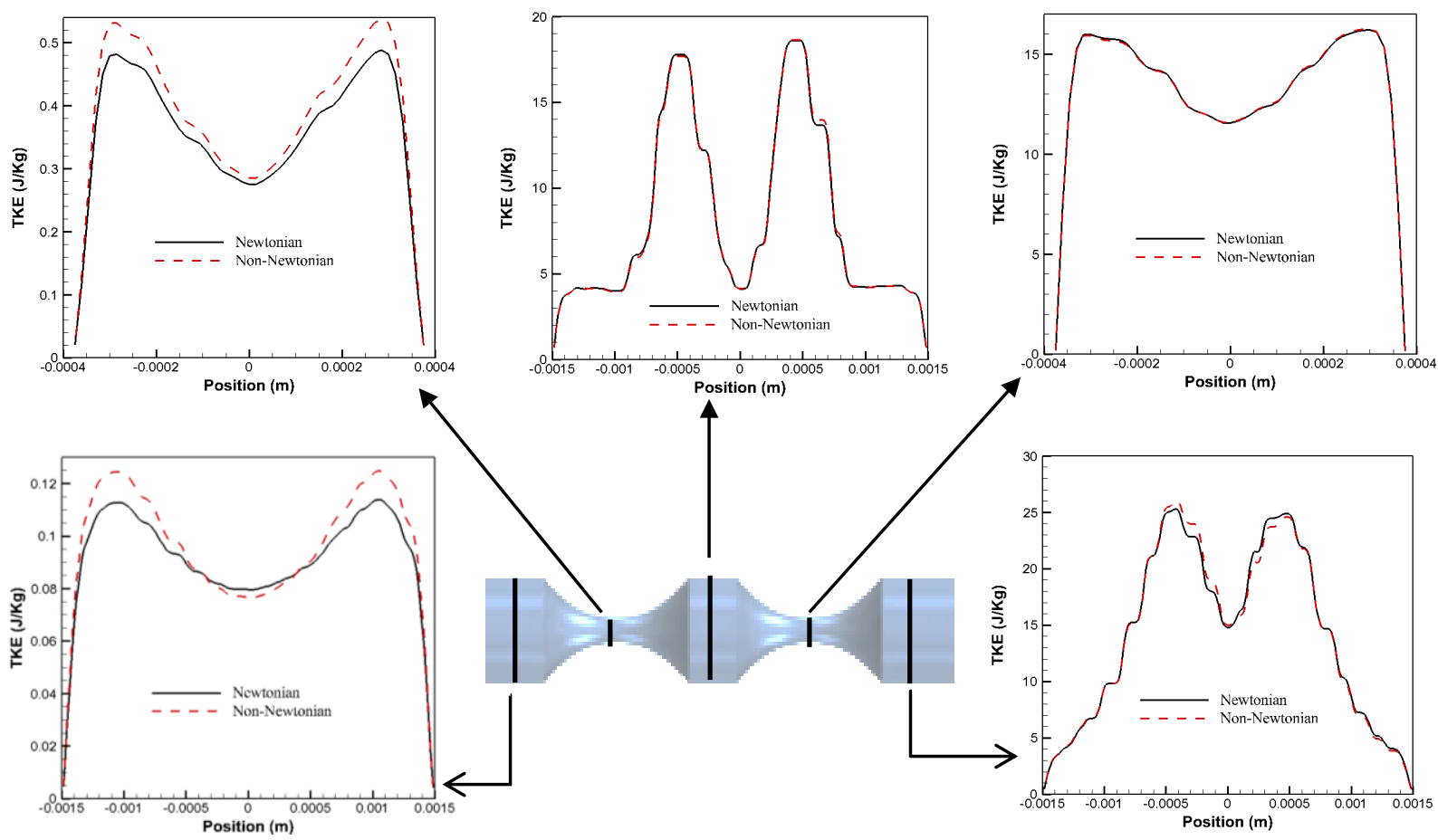

Figure 9 Turbulent Kinetic Energy (TKE) at different lines for Newtonian and Carreau models. Figure at middle indicates the position of lines. 

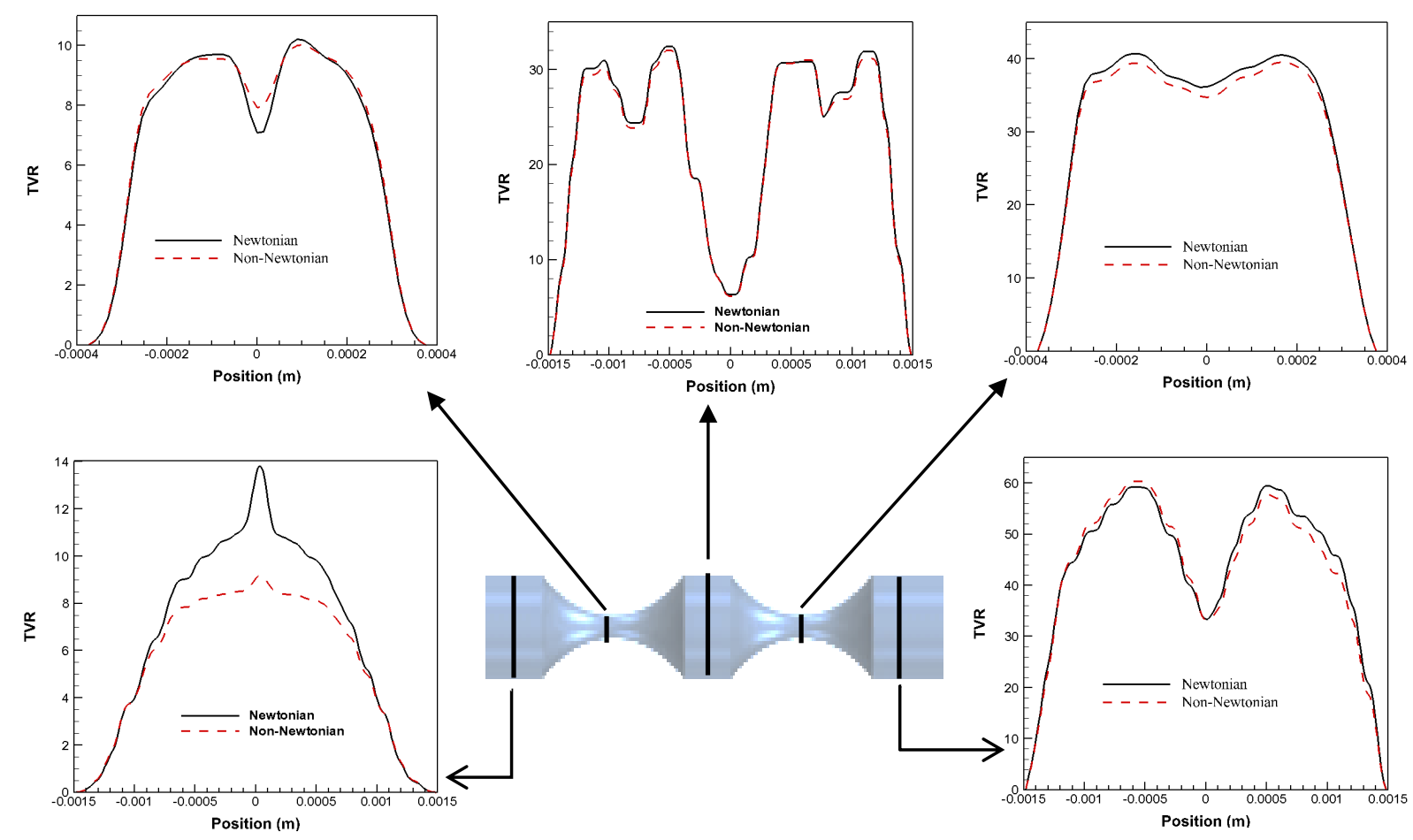

Figure 10 Turbulent Viscosity Ratio (TVR) at different lines for Newtonian and Carreau models. Figure at middle indicate the position of lines.

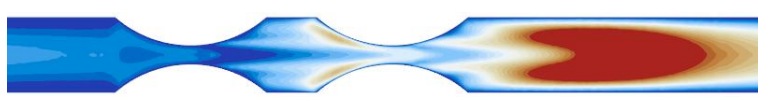

(a) Newtonian

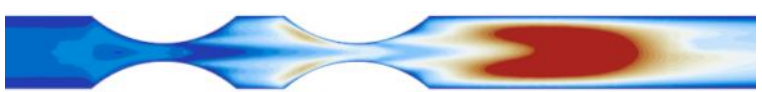

(b) Non-Newtonian

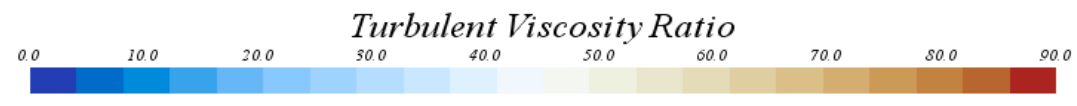

Figure 11 Contour of Turbulent Viscosity Ratio (TVR) at mid-plane for Newtonian and Carreau models.

\section{CONCLOSION}

The current numerical investigation was carried out to examine blood rheology through a double stenosis artery, assuming turbulent blood flow, using the elliptic blending Reynolds stress model and two viscosity models. Commercial CFD software was used in this study to build the mesh and solve the equation. An examination of normalised axial velocity, velocity vector, turbulent viscosity ratio, and turbulent kinetic energy advised that the TKE and TVR findings are nearly equal upstream and downstream of the stenosis, although TKE is somewhat greater with the Carreau model than with the Newtonian flow upstream and through the first stenosis. Moreover, the fractional flow reserve (FFR), which is based on pressure measurements, was utilized to check the amount of risk of stenosis through the artery. Finally, it was observed that the non-Newtonian FFR values were lower than Newtonian FFR values, indicating that non-Newtonian influences are likely to be involved.

\section{REFERENCES}

1. FRY, D. L. (1968) Acute Vascular Endothelial Changes Associated with Increased Blood Velocity Gradients.

2. Ethier, C. R., \& Simmons, C. A. (2008) Introductory Biomechanics From Cells to Organisms. Cambridge University Press,. 
3. Berger, S. A., \& Jou, L.-D. (2000) Flows in stenotic vessels. Annu. Rev. Fluid Mech, 32, 347-382.

4. Huang, C. R., Pan, W. D., Chen, H. Q., \& Copley, A. L. (1987) Thixotropic properties of whole blood from healthy human subjects. Biorheology, 24(6), 795-801. https://doi.org/10.3233/BIR-1987-24630

5. Al-Azawy, M. G., Kadhim, S. K., \& Hameed, A. S. (2020) Newtonian and nonnewtonian blood rheology inside a model of stenosis. CFD Letters, 12(11), 27-36. https://doi.org/10.37934/cfdl.12.11.2736

6. Kadhim, S. K., Al-Azawy, M. G., Ali, S. A. G., \& Kadhim, M. Q. (2021) The influence of non-Newtonian model on properties of blood flow through a left coronary artery with presence of different double stenosis. International Journal of Heat and Technology, 39(3), 895-905. https://doi.org/10.18280/ijht.390324

7. Neofytou, P., \& Drikakis, D. (2003) Effects of blood models on flows through a stenosis. International Journal for Numerical Methods in Fluids, 43(6-7), 597-635. https://doi.org/10.1002/fld.496

8. Paul, M. C., Mamun Molla, M., \& Roditi, G. (2009) Large-Eddy simulation of pulsatile blood flow. Medical Engineering and Physics, 31(1), 153-159. https://doi.org/10.1016/j.medengphy.2008.04.014

9. Mamun Molla, M., Paul, M. C., \& Roditi, G. (2010) LES of additive and non-additive pulsatile flows in a model arterial stenosis. Computer Methods in Biomechanics and Biomedical Engineering, 13(1), 105-120. https://doi.org/10.1080/10255840903062545

10. Rabby, M. G., Shupti, S. P., \& Molla, M. M. (2014) Pulsatile Non-Newtonian Laminar Blood Flows through Arterial Double Stenoses. Journal of Fluids, 2014, 1-13. https://doi.org/10.1155/2014/757902

11. Al-Azawy, M. G., Turan, A., \& Revell, A. (2016) Assessment of turbulence models for pulsatile flow inside a heart pump. Computer methods in biomechanics and biomedical engineering, 19(3), 271-285. https://doi.org/10.1080/10255842.2015.1015527

12. Al-Azawy, M. G., Turan, A., \& Revell, A. (2017) Investigating the impact of nonNewtonian blood models within a heart pump. International Journal for Numerical Methods in Biomedical Engineering, 33(1), e02780 (1-18). https://doi.org/10.1002/cnm

13. Pijls, N. H. J., Van Son, J. A. M., Kirkeeide, R. L., De Bruyne, B., \& Gould, K. L. (1993) Experimental basis of determining maximum coronary, myocardial, and collateral blood flow by pressure measurements for assessing functional stenosis severity before and after percutaneous transluminal coronary angioplasty. Circulation, 87(4), 1354-1367. https://doi.org/10.1161/01.cir.87.4.1354

14. Skopalik, S., Hall Barrientos, P., Matthews, J., Radjenovic, A., Mark, P., Roditi, G., \& Paul, M. C. (2021) Image-based computational fluid dynamics for estimating pressure drop and fractional flow reserve across iliac artery stenosis: A comparison with in-vivo measurements. International Journal for Numerical Methods in Biomedical Engineering, (January), 1-19. https://doi.org/10.1002/cnm.3437

15. Gashi, K., Bosboom, E. M. H., \& van de Vosse, F. N. (2018) The influence of model order reduction on the computed fractional flow reserve using parameterized coronary geometries. Journal of Biomechanics, 82, 313- 323. https://doi.org/10.1016/j.jbiomech.2018.11.008

16. Hoque, K. E., Ferdows, M., Sawall, S., \& Tzirtzilakis, E. E. (2020) The effect of hemodynamic parameters in patient-based coronary artery models with serial stenoses: normal and hypertension cases. Computer Methods in Biomechanics and Biomedical Engineering, 23(9), 467-475. https://doi.org/10.1080/10255842.2020.1737028

17. Simcenter. (2021) STAR-CCM+, user guide version 2021.2.1 (16.04.012-R8). 
18. Versteeg, H. K., \& Malalasekera, W. (2007) An Introduction to Computational Fluid Dynamics THE FINITE VOLUME METHOD.

19. Molla, M. M., \& Paul, M. C. (2012) LES of non-Newtonian physiological blood flow in a model of arterial stenosis. Medical engineering \& physics, 34(8), 1079-1087. https://doi.org/10.1016/j.medengphy.2011.11.013

20. Johnston, B. M., Johnston, P. R., Corney, S., \& Kilpatrick, D. (2004) Non-Newtonian blood flow in human right coronary arteries: steady state simulations. Journal of biomechanics, 37(5), 709-720. https://doi.org/10.1016/j.jbiomech.2003.09.016

21. Carreau, P. J. (1972) Rheological Equations from Molecular Network Theories. Journal of Rheology, 16(1), 99-127. https://doi.org/10.1122/1.549276

22. Manceau, R., \& Hanjalić, K. (2002) Elliptic blending model: A new near-wall Reynolds-stress turbulence closure. Physics of Fluids, 14(2), 744. https://doi.org/10.1063/1.1432693

23. Lardeau, S., \& Manceau, R. (2014) computations of complex flow configurations using a modified elliptic - Blending Reynolds - Stress model. 10th International ERCOFTAC Symposium on Engineering Turbu- lence Modelling and Measurements, hal-010517.

24. Al-Azawy, M. G., Turan, A., \& Revell, A. (2015) Assessment of turbulence models for pulsatile flow inside a heart pump. Computer methods in biomechanics and biomedical engineering, (March), 1-15. https://doi.org/10.1080/10255842.2015.1015527

25. Hariharan, P., Giarra, M., Reddy, V., Day, S. W., Manning, K. B., Deutsch, S., ... Malinauskas, R. A. (2011) Multilaboratory particle image velocimetry analysis of the FDA benchmark nozzle model to support validation of computational fluid dynamics simulations. Journal of Biomechanical Engineering, 133(4), 1-14. https://doi.org/10.1115/1.4003440 